Article

\title{
Estimation of Particulate Matter Impact on Human Health within the Urban Environment of Athens City, Greece
}

\author{
Konstantinos P. Moustris ${ }^{1, *}$, Kleopatra Ntourou ${ }^{1}$ and Panagiotis T. Nastos ${ }^{2}$ \\ 1 Laboratory of Fluid Mechanics, Mechanical Engineering Department, Piraeus University of \\ Applied Sciences, 250 Thivon and P. Ralli Str., GR-12244 Athens, Greece; kntourou@puas.gr \\ 2 Laboratory of Climatology and Atmospheric Environment, Faculty of Geology and Geoenvironment, \\ University of Athens, Panepistimiopolis Camp, GR-15784 Athens, Greece; nastos@geol.uoa.gr \\ * Correspondence: kmoustris@puas.gr; Tel.: +30-210-538-1234
}

Academic Editor: Michael Peter Smith

Received: 13 November 2016; Accepted: 14 January 2017; Published: 20 January 2017

\begin{abstract}
The main objective of this work is the assessment of the annual number of hospital admissions for respiratory diseases (HARD) due to the exposure to inhalable particulate matter $\left(\mathrm{PM}_{10}\right)$, within the greater Athens area (GAA), Greece. To achieve this aim, on the one hand, time series of the particulate matter with aerodynamic diameter less than $10 \mu \mathrm{m}\left(\mathrm{PM}_{10}\right)$ recorded in six monitoring stations located in the GAA, for a 13-year period 2001-2013, have been statistically analyzed. On the other hand, the AirQ2.2.3 software developed by the World Health Organization (WHO) was used to evaluate adverse health effects by $\mathrm{PM}_{10}$ in the GAA during the examined period. The results show that, during the examined period, $\mathrm{PM}_{10}$ concentrations present a significant decreasing trend. Also, the mean annual HARD cases per 100,000 inhabitants ranged between 20 (suburban area) and 40 (city center area). Approximately 70\% of the annual HARD cases are due to city center residents. In all examined sites, a declining trend in the annual number of HARD cases appears. Moreover, a strong relation between the annual number of HARD cases and the annual number of days exceeding the European Union daily $\mathrm{PM}_{10}$ threshold value was found.
\end{abstract}

Keywords: particulate matter; AirQ model; hospital admission respiratory disease; Athens; Greece

\section{Introduction}

Various epidemiological studies have shown the significant impacts of urban air pollution on human health. More concretely, several epidemiological studies have shown that the adverse health effects are related to both short- and long-term exposure to inhalable particulate matter [1-5].

During the last decade, many researchers have used the AirQ2.2.3 model, which has been developed by the World Health Organization (WHO) in order to investigate the influence of air pollution on public health and to estimate the adverse effects of air pollution on human health, especially in an urban populated environment [6-12]. Shakour et al. [6] investigated the levels of particulate matter in selected sites in Cairo city, Egypt. The selected sites were chosen to present different activities at north and south areas of Cairo city. They applied the AirQ2.2.3 model in order to calculate the risk on human communities as a result of particulate matter exposure. The output results showed that quantifying the impact of air pollution on the public's health has become an increasingly critical component in policy discussion.

Fattore et al. [7] applied the AirQ2.2.3 model in two different small municipalities in a highly industrialized area of Northern Italy in order to investigate the influence of particulate matter, ozone 
and nitrogen dioxide exposure on human health. According to their results the AirQ2.2.3 model seems to be an effective tool for such researches, helpful in decision-making.

Goudarzi et al. [8] used the AirQ2.2.3 model to evaluate adverse health effects caused by nitrogen dioxide exposure in Ahvaz city, Iran during 2009. They found that approximately 3\% of total cardiovascular mortality, acute myocardial infarction, and hospital admission for chronic obstructive pulmonary disease happened when the nitrogen dioxide concentrations were more than $20 \mu \mathrm{g} / \mathrm{m}^{3}$. Low percentage of the observed health endpoints was associated with low concentration of measured nitrogen dioxide.

Naddafi et al. [9] applied the AirQ2.2.3 model in Tehran city, Iran in order to assess adverse health effects due to the exposure to particulate matter, ozone, nitrogen dioxide and sulfur dioxide. Results indicated that the estimated magnitude of the health impact underscores the need for urgent actions to reduce the health burden of air pollution.

Jeong [10], in order to estimate the short-term mortality impact of air pollution, applied the approach suggested by the World Health Organization (WHO), using the AirQ2.2.3 model. Daily concentrations of particulate matter, ozone, nitrogen dioxide and sulfur dioxide were used to assess human exposure and health effects, in terms of attributable proportion of the health outcome, annual number of excess cases of mortality for all causes, and cardiovascular and respiratory diseases. The results are also in line with those of other international studies that apply the AirQ model.

Habeebullah [11] investigated the health impacts of atmospheric particles with an aerodynamic diameter of 10 microns or less $\left(\mathrm{PM}_{10}\right)$ in Makkah city, Kingdom of Saudi Arabia, applying the AirQ2.2.3 model. The results of the model were discussed and compared with several studies conducted in other countries around the world.

Moustris et al. [12] applied the AirQ2.2.3 model in order to evaluate adverse health effects by $\mathrm{PM}_{10}$ pollution in the coastal city of Volos, Greece, during a 5-year period (2007-2011). The results of the study indicated that when the mean annual $\mathrm{PM}_{10}$ concentration exceeds the corresponding European Union (EU) threshold value [13], the number of hospital admissions for respiratory diseases (HARD) associated with $\mathrm{PM}_{10}$ increases by $25 \%$ on average. Also, they estimated an increase of about $2.5 \%$ in HARD compared to the expected annual HARD cases for Volos. Furthermore, a strong correlation was found between the number of days exceeding the EU daily threshold concentration $\left(\left[\mathrm{PM}_{10}\right] \geq 50 \mu \mathrm{g} / \mathrm{m}^{3}\right)[13]$ and the annual HARD cases.

Finally, Omidi et al. [14] assessed the health risks associated with nitrogen dioxide in the city of Kermanshah, the capital of Kermanshah province, Iran. According to their findings, several immediate measures should be taken by the government to control the levels of nitrogen dioxide in the atmosphere to confine the related cases of mortality and morbidity.

In this study, an effort was made to assess the annual number of hospital admissions for respiratory diseases (HARD) due to the exposure of inhalable particulate matter $\left(\mathrm{PM}_{10}\right)$, within the greater Athens area (GAA), Greece, for a 13-year period 2001-2013.

\section{Materials and Methods}

The GAA, like most metropolitan areas in the world, faces severe air pollution problems due to high population density and the accumulation of major economic activities in this region. The contribution of the intense sunshine to the high levels of photochemical air pollution, especially during summer months, is significant. The air pollution problems are often exacerbated by factors that favor the accumulation of air pollutants over the city, such as topography (basin is surrounded by mountains), narrow and deep street canyons and adverse meteorological conditions, such as temperature inversions, low wind speed, high air temperature, extensive periods of dryness $[15,16]$.

For the estimation of HARD cases, the mean daily concentrations of $\mathrm{PM}_{10}$ used in this research were acquired from six stations of the network of the Greek Ministry of Environment and Energy (GMEE) during the 13-year period 2001-2013. Monitoring stations are classified as center city (CC) or suburban (S) ones, by their location, and also as traffic (T) or back-ground (BG) ones, by their 
categorization (Table 1). BG stations measure the air pollution from all sources against traffic regarding $\mathrm{T}$ stations. The population in Table 1 refers to the whole city-municipality where the air pollution station is located (2011 census).

Table 1. List of locations of stations and related information.

\begin{tabular}{cccccc}
\hline Station & $\begin{array}{c}\text { Abbreviated } \\
\text { Station Name }\end{array}$ & Area & Population & Longitude & Latitude \\
\hline Agia Paraskevi & AGP & S-BG & 60,000 & $37^{\circ} 59^{\prime} 42^{\prime \prime}$ & $23^{\circ} 49^{\prime} 10^{\prime \prime}$ \\
Lykovrissi & LYK & S-T & 31,000 & $38^{\circ} 04^{\prime} 11^{\prime \prime}$ & $23^{\circ} 46^{\prime} 35^{\prime \prime}$ \\
Maroussi & MAR & S-T & 73,000 & $38^{\circ} 01^{\prime} 51^{\prime \prime}$ & $23^{\circ} 47^{\prime} 14^{\prime \prime}$ \\
Thrakomakedones & THR & S-BG & 107,000 & $38^{\circ} 08^{\prime} 37^{\prime \prime}$ & $23^{\circ} 45^{\prime} 29^{\prime \prime}$ \\
Piraeus & PIR & CC-T & 164,000 & $37^{\circ} 56^{\prime} 36^{\prime \prime}$ & $23^{\circ} 38^{\prime} 51^{\prime \prime}$ \\
Aristotelous & ARI & CC-T & 664,000 & $37^{\circ} 59^{\prime} 16^{\prime \prime}$ & $23^{\circ} 43^{\prime} 39^{\prime \prime}$ \\
\hline
\end{tabular}

In order to estimate the annual number of HARD cases within the GAA, the Air Quality Health Impact Assessment Tool (AirQ2.2.3) was applied. The AirQ2.2.3 model enables the user to assess the potential impact of exposure to a given air pollutant on human health in a defined urban area during a certain time period. The model requires the following data [6-12,14]:

I. The coordinates of the monitoring site.

II. The total exposed population which is assumed to be the population of the whole city-municipality where the air pollution monitoring station is located.

III. The number of days in which the mean daily $\mathrm{PM}_{10}$ concentration falls within categories of intervals of $10 \mu \mathrm{g} / \mathrm{m}^{3}$ (e.g., 0-9, 10-19, 20-29 $\mathrm{\mu g} / \mathrm{m}^{3}$, etc.).

IV. The annual and seasonal arithmetic mean of mean daily values.

V. The annual 98th percentile of mean daily values.

VI. The annual and seasonal maximum daily values.

VII. The relative risk (RR).

The AirQ2.2.3 model can be used to estimate the cumulative number of cases per 100,000 inhabitants for each concentration range, the associated relative risk, and the number of HARD cases [6-12,14].

\section{Results and Discussion}

Initially, a statistical processing of the mean daily concentrations of $\mathrm{PM}_{10}$ during the examined period 2001-2013 was carried out. Figure 1 depicts the variation of the mean annual $\mathrm{PM}_{10}$ concentrations for the six examined locations within the GAA.

According to Figure 1, the time series of the mean annual $\mathrm{PM}_{10}$ concentrations depict significant decreasing trends in all six examined sites (see Table 1). It was found that the annual decreasing trend ranges between $-0.3 \mu \mathrm{g} / \mathrm{m}^{3}$ per year (THR) and $-2.4 \mu \mathrm{g} / \mathrm{m}^{3}$ per year (LYK). Furthermore, MAR, LYK ARI and PIR seem to present mean annual concentrations of $\mathrm{PM}_{10}$ above the EU annual threshold $\left(40 \mu \mathrm{g} / \mathrm{m}^{3}\right)$ until 2010, however $\mathrm{PM}_{10}$ concentrations for all the examined stations remain below the EU annual threshold during the period 2011-2013.

Figure 2 shows the mean monthly $\mathrm{PM}_{10}$ concentrations within the GAA during the period 2001-2013. It is obvious that in all cases, there is a significant seasonality. More specifically, during the cold period of the year (October-April) in four of the examined sites (ARI, LYK, MAR and PIR) the mean monthly $\mathrm{PM}_{10}$ concentrations are higher than in the warm period of the year (May-September). This is mainly due to the traffic and secondarily due to the use of oil and wood heating systems as well. Concerning the two remaining sites (AGP and THR) things look totally different. During the cold period of the year, the mean monthly $\mathrm{PM}_{10}$ concentrations are less than the corresponding concentrations during the warm period of the year. In our opinion, this is due to different sources of 
$\mathrm{PM}_{10}$ that appeared in these areas. In four of them (ARI, LYK, MAR and PIR), which are characterized as traffic (T) or city center (CC) areas (see Table 2), it seems that the $\mathrm{PM}_{10}$ sources concern mainly vehicles' traffic air pollution in contrast to the two other suburban-background (S-BG) areas (AGP and THR). Higher concentrations may also be due to different meteorological conditions in warm and cold periods of the year, such as different mixing heights, different wind speeds, etc. The suburban-background areas are not influenced by a specific type of source, but by a synergy of sources (e.g., wind erosion, industry, traffic, heating, etc.).

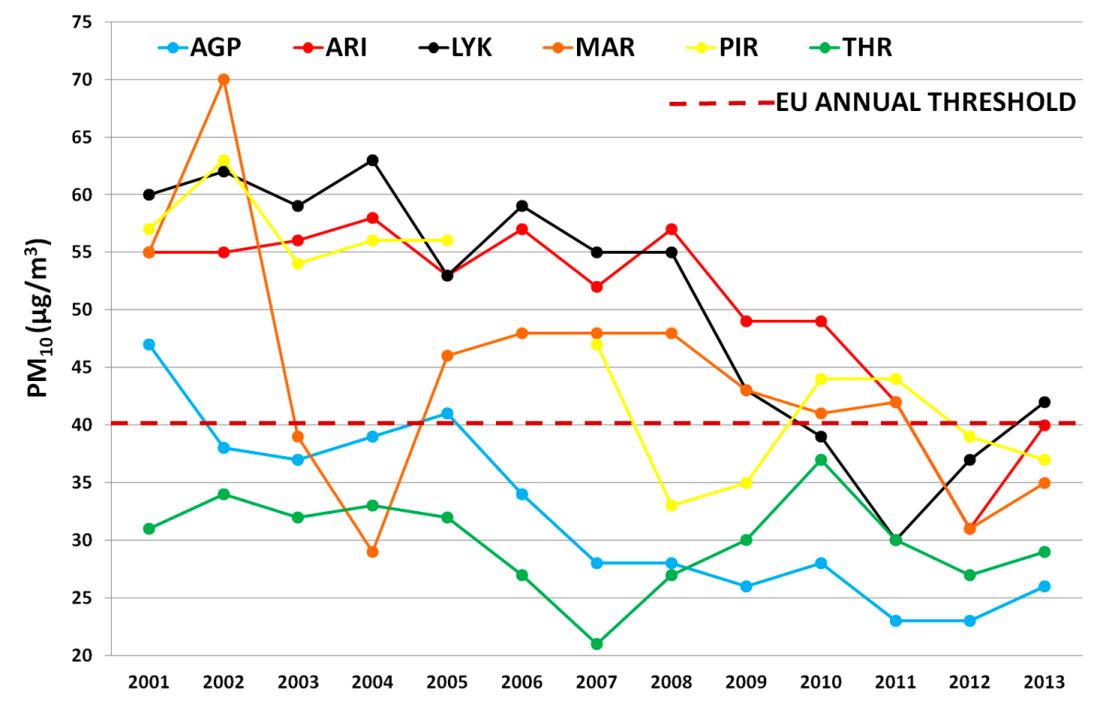

Figure 1. Mean annual $\mathrm{PM}_{10}$ concentrations within the GAA.

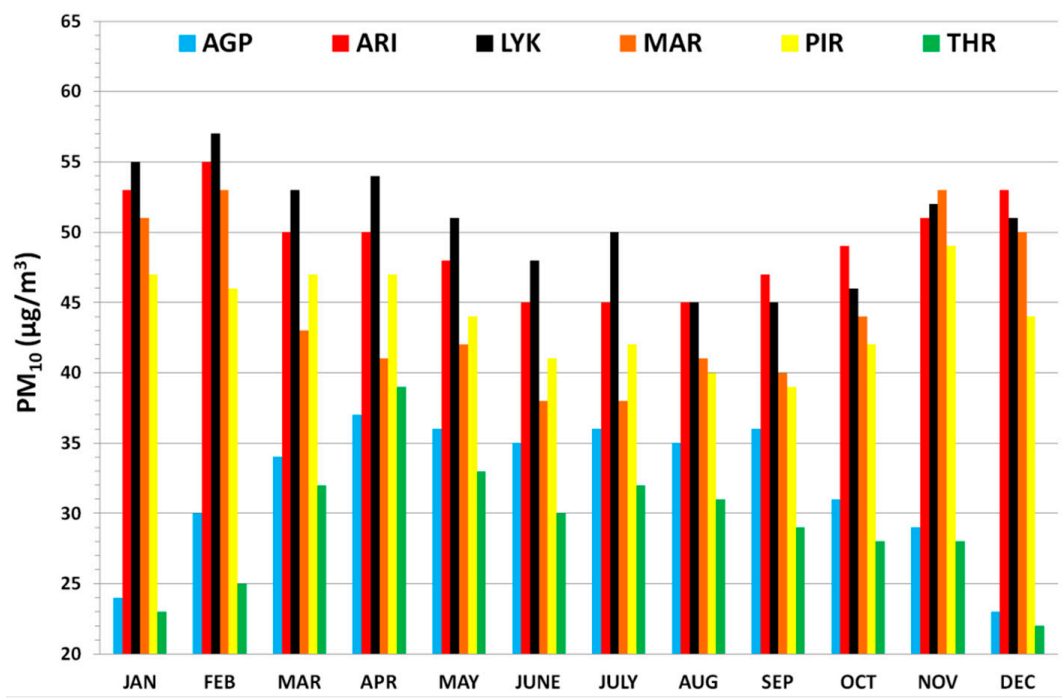

Figure 2. Mean monthly $\mathrm{PM}_{10}$ concentrations within the GAA.

In Figure 3, the mean intra weekly variation of $\mathrm{PM}_{10}$ concentrations within the GAA during the warm (a) and the cold (b) period of the year is depicted. Higher $\mathrm{PM}_{10}$ concentrations appear during the cold period of the year against the warm period of the year, except AGP and THR. However, lower $\mathrm{PM}_{10}$ concentrations dominate during the weekend against working days of the week, in all examined areas. This leads to the conclusion that the vehicular traffic is the main $\mathrm{PM}_{10}$ source; during weekends on one hand, many inhabitants are likely to leave the city center for short excursions in the countryside and on the other hand, most of the others who remain in the city center do not use their vehicles. 


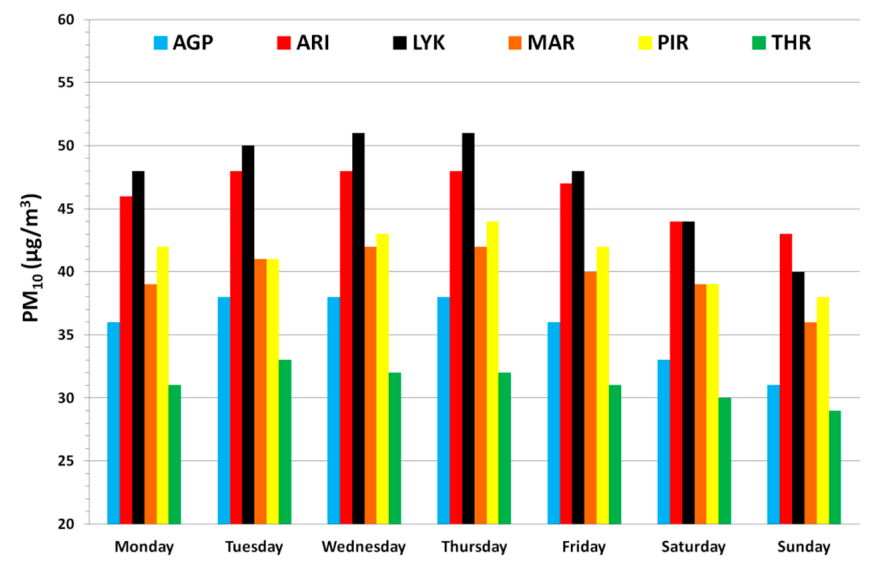

(a)

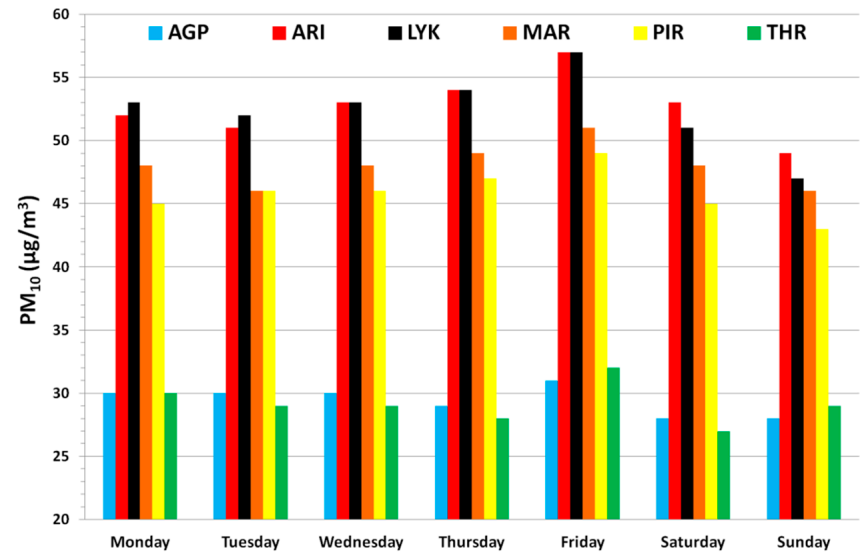

(b)

Figure 3. Mean intra weekly variation of $\mathrm{PM}_{10}$ concentrations within the GAA during the warm period of the year (a) and during the cold period of the year (b).

The EU Directive 2008/50/EC [13] on ambient air quality and cleaner air for Europe determines $50 \mu \mathrm{g} / \mathrm{m}^{3}$ as a daily threshold concentration of $\mathrm{PM}_{10}$. Thus, every day when the mean daily $\mathrm{PM}_{10}$ concentration is above $50 \mu \mathrm{g} / \mathrm{m}^{3}$ is considered as an exceedance day. According to the EU Directive 2008/50/EC [13], the number of exceedance days must be less than 35 days per year (in other words less than $9.6 \%$ of the days of a year). The annual number of the exceedances was calculated for each site during the period 2001-2013 (Figure 4).

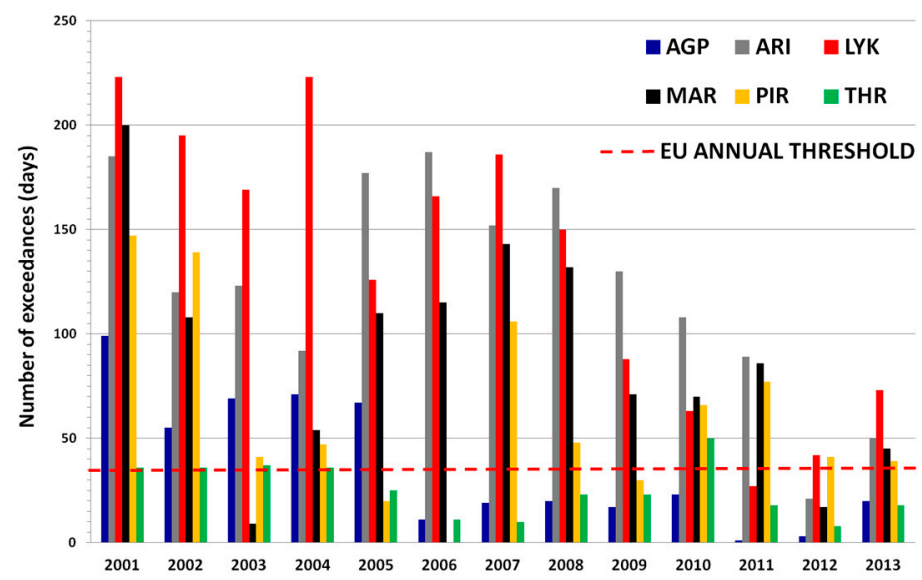

Figure 4. Annual number of exceedance days $\left(\left[\mathrm{PM}_{10}\right] \geq 50 \mu \mathrm{g} / \mathrm{m}^{3}\right)$ within the GAA. 
According to Figure 4, it is clear that the annual number of exceedances appears to be higher than the EU threshold of about 35 days per year (dot line in Figure 4) in four of the six examined sites within the GAA (ARI, LYK, MAR and PIR). However, through the years, a significant decreasing trend is presented. Regarding the AGP site, one can see that the exceedances appearing during the period 2001-2005 are eliminated thereafter. There is not any major problem concerning the annual number of exceedance days that appeared in THR site; for most of the examined years, it is lower than the EU corresponding threshold, except the period 2001-2004 where the exceedances stay around the EU annual threshold and 2010 where they are slightly higher than the EU annual threshold.

Subsequently, the AirQ2.2.3 model was applied for each one of the six examined sites in order to calculate the annual number of HARD cases. Figure 5 depicts the cumulative annual number of HARD cases due to $\mathrm{PM}_{10}$ per interval of $10 \mu \mathrm{g} / \mathrm{m}^{3}$ per 100,000 inhabitants within the GAA. More specifically, the $y$ axis represents the number of HARD cases and the $x$ axis represents the mean daily $\mathrm{PM}_{10}$ concentration per interval of $10 \mu \mathrm{g} / \mathrm{m}^{3}$.
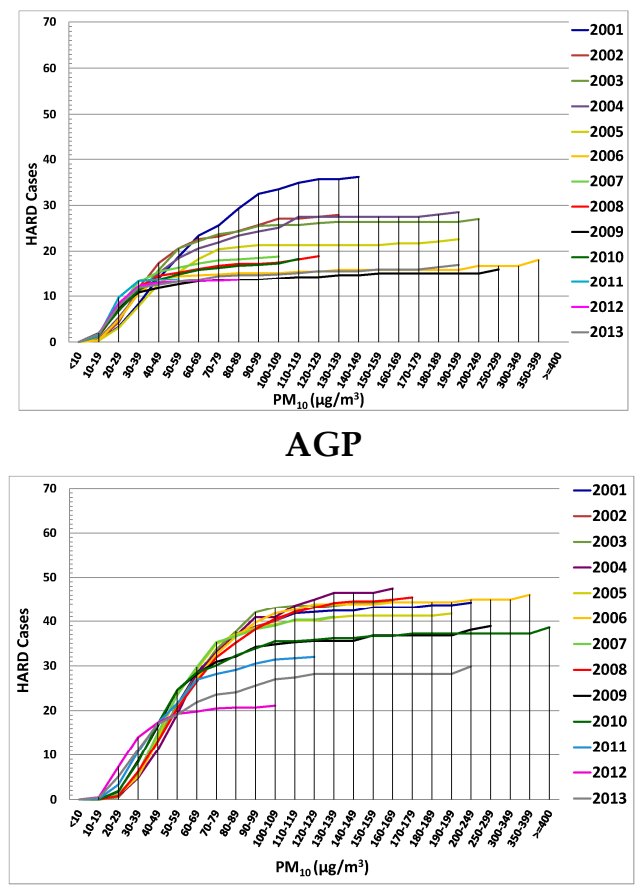

ARI

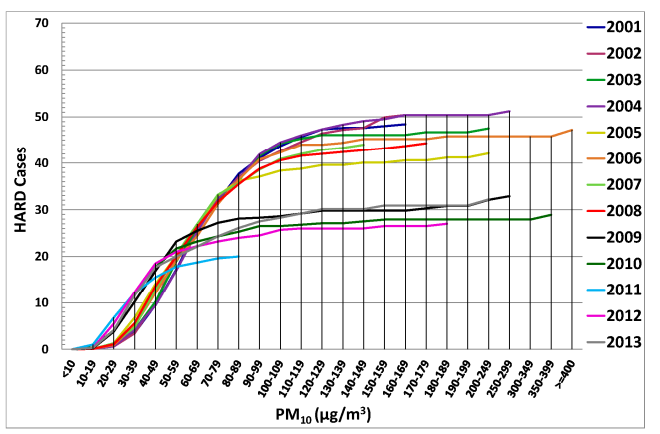

LYK

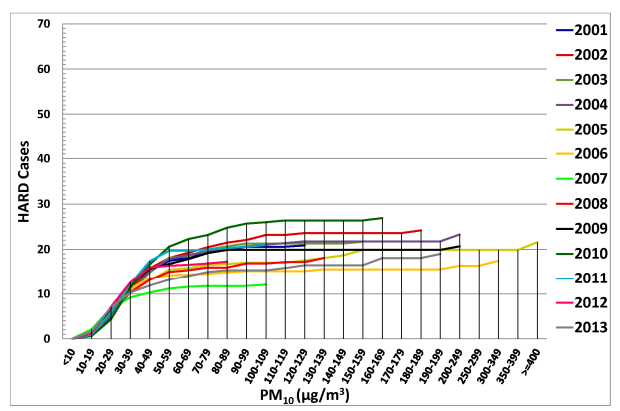

THR

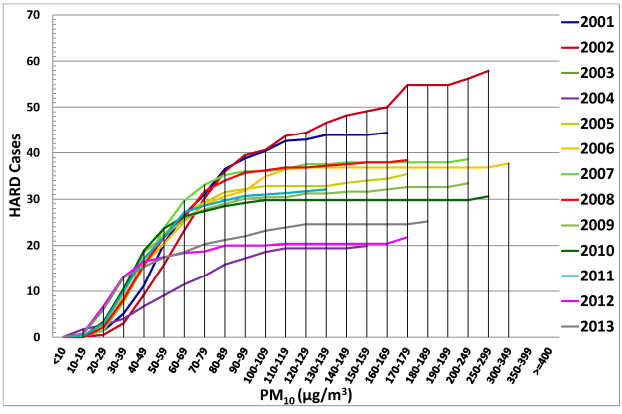

MAR

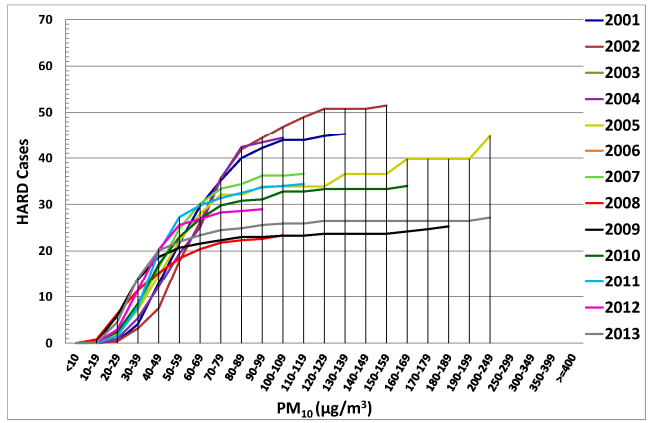

PIR

Figure 5. Cumulative annual number of HARD cases due to $\mathrm{PM}_{10}$ within the GAA.

Four of the examined sites (ARI, MAR, LYK and PIR) present almost the same pattern. Furthermore, the two other sites (AGP and THR) show protective conditions with a lower number of HARD cases per year. 
In order to compare the annual number of HARD cases between the different areas within the GAA, the annual number of HARD cases was normalized per 100,000 inhabitants with the application of the AirQ2.2.3 model. In Figure 6, the percentage (\%) of the annual number of HARD cases due to $\mathrm{PM}_{10}$ exposure during the examined period in each studied area per 100,000 inhabitants is depicted. The highest rate of about $21 \%$ appears in ARI and LYK, followed by 19\% in PIR and 17\% in MAR, while the lowest rate of about $11 \%$ appears in THR and AGP.

The mean annual number of HARD cases per 100,000 inhabitants for each studied area during the examined period 2001-2013 reveals that LYK, ARI, PIR and MAR are the most vulnerable areas $(35 \leq$ HARD $\leq 40)$ followed by AGP and THR $(20 \leq$ HARD $\leq 22)$.

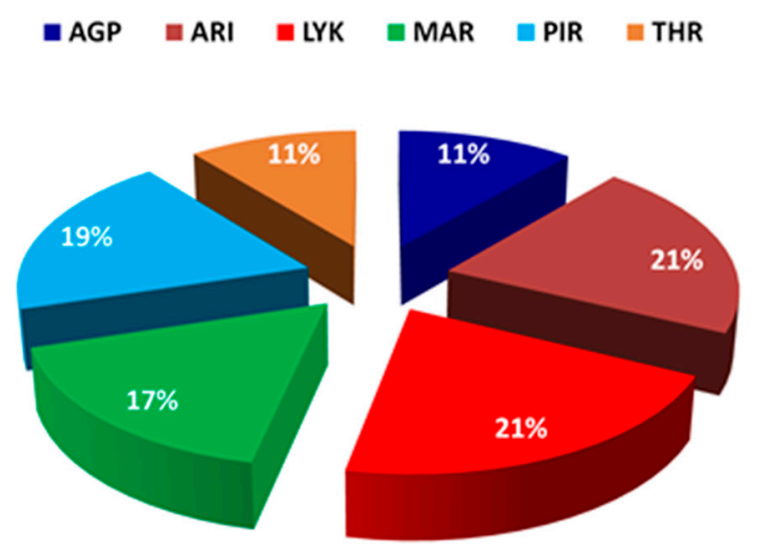

Figure 6. Percentage of the annual number of HARD cases due to $\mathrm{PM}_{10}$ exposure in each studied site per 100,000 inhabitants.

In order to provide quantitative relations for the temporal variability of the annual number of HARD cases per 100,000 inhabitants and the annual means of $\mathrm{PM}_{10}$ concentrations during the examined 13-year period, scatter diagrams were constructed (Figure 7a,b). Figure 7a depicts that the linear model interprets $91.2 \%$ of the variance $\left(R^{2}=0.912\right)$ of the annual HARD cases. Moreover, the linear model explains $90.1 \%$ of the variance $\left(R^{2}=0.901\right)$ of the mean annual $\mathrm{PM}_{10}$ concentrations (Figure $7 \mathrm{~b}$ ). According to the performed analysis, during the 13-year period, strong decreasing trend patterns appear in both annual HARD cases per 100,000 inhabitants (Figure 7a) and mean annual $\mathrm{PM}_{10}$ concentration values (Figure $7 \mathrm{~b}$ ) all over the GAA.

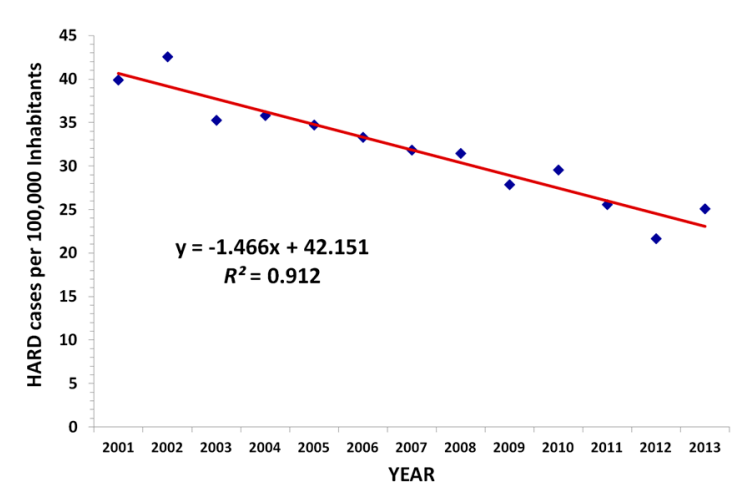

(a)

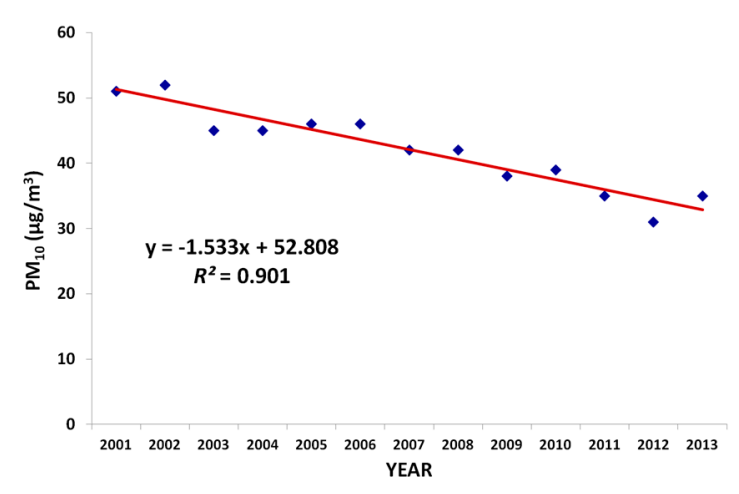

(b)

Figure 7. Temporal variability of annual HARD cases per 100,000 inhabitants (a) and mean annual $\mathrm{PM}_{10}$ concentrations (b), within the GAA.

Figure 8 presents the spatial distribution of the mean annual HARD cases within the GAA in relation to the total population and the activities in each examined area. The center of Athens (ARI) 
is the most densely populated and air polluted area, presenting an annual number of HARD cases ranging from 60 to 262 cases, always based on the population of about 664,000 inhabitants. The port of the GAA (PIR) follows due to shipping activities presenting an annual number of HARD cases from 30 to 60 cases. Finally, all the other areas present lower HARD cases from 0 up to 30, always based on their population (see Table 1).

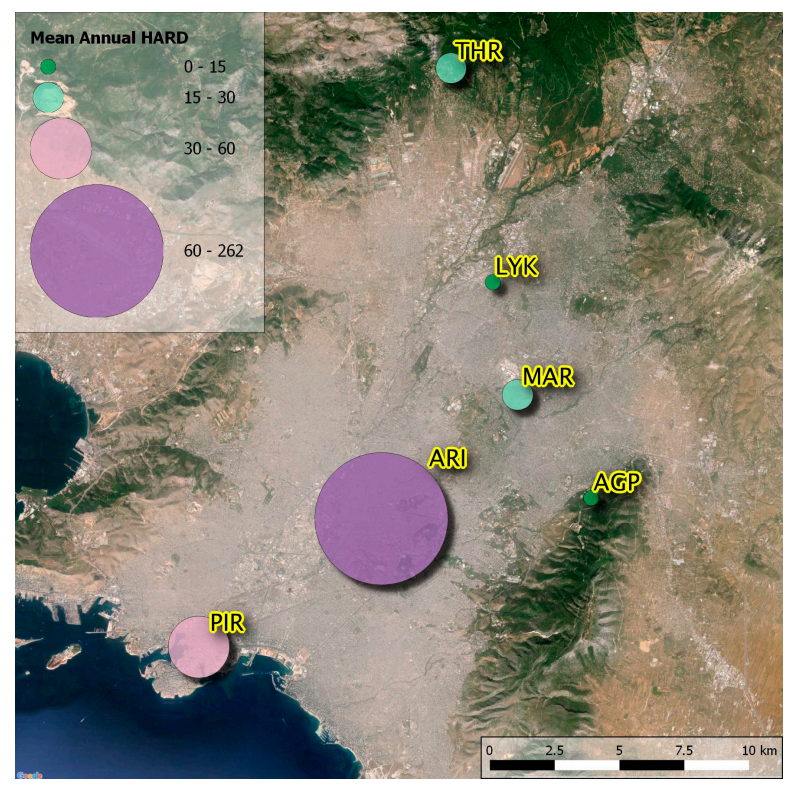

Figure 8. Spatial distribution of the mean annual HARD cases during the period 2001-2013, based on the population of each area.

Finally, the quantitative relation between the annual number of HARD cases and the annual number of days where $\mathrm{PM}_{10}$ concentrations exceed the European Council (EC) threshold of $50 \mu \mathrm{g} / \mathrm{m}^{3}$ [13] was investigated. Figure 9 indicates that the exponential fitting model explains $77.7 \%$ $\left(R^{2}=0.777\right)$ of the variance of the annual HARD cases. Furthermore, when the number of exceedance days is greater than or equal to 35 , then the number of HARD cases due to $\mathrm{PM}_{10}$ exposure increases abruptly. This seems to be in full agreement with the limit number of 35 exceedance days per year, which has been established by the EU for the protection of public health.

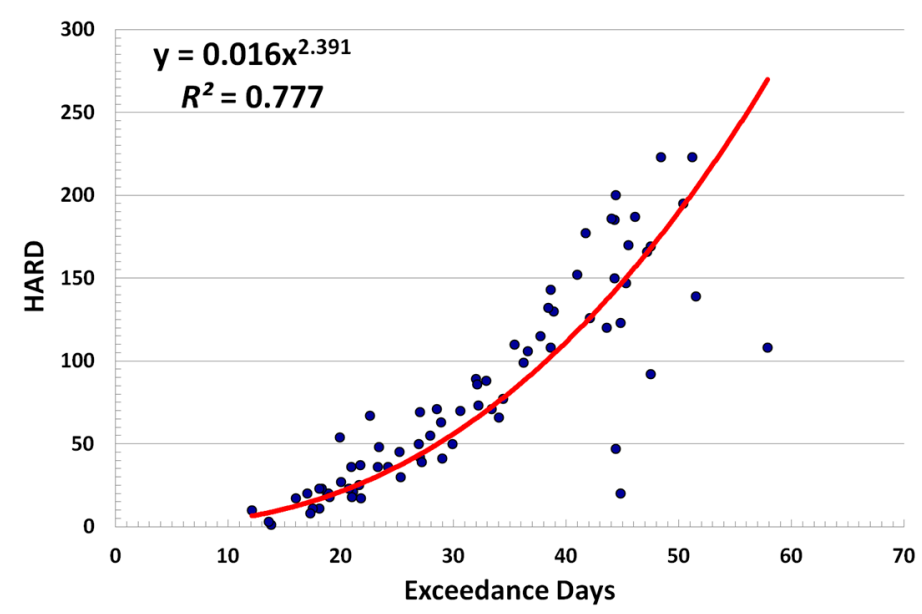

Figure 9. Scatter plot between annual HARD cases versus annual number of exceedance days $\left(\left[\mathrm{PM}_{10}\right] \geq 50 \mu \mathrm{g} / \mathrm{m}^{3}\right)$ in the GAA. The solid red line represents the exponential fitting model. 
Table 2 presents a comparative analysis of HARD cases per 100,000 inhabitants due to $\mathrm{PM}_{10}$ exposure for different sites worldwide. It seems that only Volos city, Greece, and Suwon city, Seoul, South Korea, can be compared with the six examined sites within the GAA and in general within Athens city, the capital city of Greece. In all these cities, the mean annual $\mathrm{PM}_{10}$ concentrations range from $30 \mu \mathrm{g} / \mathrm{m}^{3}$ to $50 \mu \mathrm{g} / \mathrm{m}^{3}$ and the annual number of HARD cases per 100,000 inhabitants varies between 20 and 40 cases. The capital city of Tehran, Iran, follows with a mean annual $\mathrm{PM}_{10}$ concentration of about $90.6 \mu \mathrm{g} / \mathrm{m}^{3}$ and a mean annual number of HARD cases of around 77 cases per year. It is worth noting that the holy city of Makkah, Saudi Arabia, and the capital city of Cairo, Egypt, face significant $\mathrm{PM}_{10}$ exceedances, having a great impact on HARD cases per year.

Table 2. Comparative analysis of HARD cases per 100,000 inhabitants due to $\mathrm{PM}_{10}$ exposure for different sites worldwide.

\begin{tabular}{|c|c|c|c|c|c|}
\hline Location & Period & $\begin{array}{c}\text { Mean Annual } \text { PM }_{10} \\
\text { Concentration } \\
\left(\mu \mathrm{g} / \mathrm{m}^{3}\right)\end{array}$ & $\begin{array}{c}\text { Number of HARD } \\
\text { Cases Per 100,000 } \\
\text { Inhabitants }\end{array}$ & $\mathbf{R R}$ & Reference \\
\hline Volos, Greece & 2007-2011 & 41.2 & 32 & 1.008 & [12] \\
\hline $\begin{array}{l}\text { Suwon City, Seoul, } \\
\text { South Korea }\end{array}$ & 2011 & 52.0 & 39 & 1.008 & [10] \\
\hline Tehran, Iran & 2010 & 90.6 & 77 & 1.008 & [9] \\
\hline $\begin{array}{l}\text { Holy City of Makkah, } \\
\text { Saudi Arabia }\end{array}$ & 2012-2013 & 195.5 & 2504 & 1.096 & [11] \\
\hline $\begin{array}{l}\text { South Shoubra El-Kheima, } \\
\text { Cairo, Egypt }\end{array}$ & 2008-2009 & 267.0 & 4919 & 1.274 & [6] \\
\hline $\begin{array}{l}\text { North Shoubra El-Kheima, } \\
\text { Cairo, Egypt }\end{array}$ & 2008-2009 & 306.0 & 10,941 & 1.138 & [6] \\
\hline $\begin{array}{l}\text { North Helwan, } \\
\text { Cairo, Egypt }\end{array}$ & 2008-2009 & 382.0 & 5002 & 1.290 & [6] \\
\hline $\begin{array}{l}\text { South Helwan, } \\
\text { Cairo, Egypt }\end{array}$ & 2008-2009 & 441.0 & 4053 & 1.377 & [6] \\
\hline $\begin{array}{l}\text { Aristotelous (Athens city } \\
\text { center), Greece }\end{array}$ & 2001-2013 & 50.1 & 40 & 1.008 & Present work \\
\hline Lykovrissi, Greece & 2001-2013 & 50.3 & 40 & 1.008 & Present work \\
\hline Maroussi, Greece & 2001-2013 & 44.5 & 35 & 1.008 & Present work \\
\hline Piraeus (port), Greece & 2001-2013 & 44.2 & 36 & 1.008 & Present work \\
\hline Agia Paraskevi, Greece & 2001-2013 & 32.1 & 21 & 1.008 & Present work \\
\hline Thrakomakedones, Greece & 2001-2013 & 30.0 & 20 & 1.008 & Present work \\
\hline
\end{tabular}

\section{Conclusions}

The main objective of this study was the estimation of the annual number of HARD cases attributed to $\mathrm{PM}_{10}$ exposure in the greater Athens area by applying the AirQ2.2.3 model. Results showed that there is a strong relationship between the HARD cases and $\mathrm{PM}_{10}$ exposure levels. Also, decreasing trends for both the annual number of HARD cases and the mean annual $\mathrm{PM}_{10}$ concentrations within the GAA during the 13 years period were found.

The GAA seems to have better atmospheric conditions against other metropolitan cities, such as the holy city of Makkah, Saudi Arabia, and the city of Cairo, Egypt, even taking into account the large amounts of particulate matter transported from the Saharan desert $[17,18]$. During the last years, the air quality (concerning $\mathrm{PM}_{10}$ ) is getting better, having a protective impact on public health. According to our knowledge, this is the result of a number of different measures and actions that have been taken by the state, such as: 
(1) Since 2000, the metro (underground) with two new lines began operating, servicing about $1,000,000$ people per day. This means that a mean number of about 250,000 vehicles are not in use within the GAA, improving the air quality.

(2) Since 2001, the new International Airport began operating. In contrast with the new airport, the old one was very close to the city and the sea. Thus, the south wind transfers pollutants within the GAA, which are trapped due to the surrounding high mountains.

(3) Since 2002, the new highway through the GAA, called Attiki Odos, began operating. This highway is located from east to west, connecting the most densely populated areas of the GAA with the new International Airport. Lower emissions of pollutants in the atmosphere appear due to the fact that the cars are running at high speeds.

(4) Since 2002, the Bus Lanes (BL) began operating within the GAA. These BL are exclusively for buses only. As a result, the mean speed of buses was increased significantly. Thus, fewer buses are able to cover the same distance in less time than before. By this way, there is lower pollutants emission and also buses become more attractive to the public, thus reducing the number of private vehicles on the streets.

(5) Finally, the economic crisis since 2008 has prevented people from using their cars and using oil for heating, reducing oil consumption and pollutants emissions as well.

Further investigation is required in order to estimate the adverse health effects due to other pollutants, such as nitrogen dioxide, sulfur dioxide, ozone, carbon monoxide, volatile hydrocarbons, etc.

Author Contributions: Konstantinos P. Moustris, Kleopatra Ntourou and Panagiotis T. Nastos conceived and designed this work. Furthermore, all authors were collaborated to analyze the data and write the whole paper.

Conflicts of Interest: The authors declare no conflict of interest.

\section{References}

1. Dockery, D.W.; Schwartz, J.; Spengler, J.D. Air pollution and daily mortality: Association with particulates and acid aerosols. Environ. Res. 1992, 59, 362-373. [CrossRef]

2. Katsouyanni, K. Ambient air pollution and health. Br. Med. Bull. 2003, 68, 143-156. [CrossRef] [PubMed]

3. Paliatsos, A.G.; Priftis, K.N.; Ziomas, I.C.; Panagiotopoulou-Gartagani, P.; Nikolaou-Panagiotou, A.; Tapratzi-Potamianou, P.; Zachariadi-Xypolita, A.; Nicolaidou, P.; Saxoni-Papageorgiou, P. Association between ambient air pollution and childhood asthma in Athens, Greece. Fresenius Environ. Bull. 2006, 15, 614-618.

4. Pope, C.A., III; Dockery, D.W. Health effects of fine particulate air pollution: Lines that connect. J. Air Waste Manag. Assoc. 2006, 56, 709-742. [CrossRef] [PubMed]

5. Nastos, P.T.; Paliatsos, A.G.; Anthracopoulos, M.B.; Roma, E.S.; Priftis, K.N. Outdoor particulate matter and childhood asthma admissions in Athens, Greece: A time-series study. Environ. Health 2010, 9, 45. [CrossRef] [PubMed]

6. Shakour, A.A.; El-Shahat, M.F.; El-Taieb, N.M.; Hassanein, M.A.; Mohamed, A.M.F. Health impacts of particulate matter in greater Cairo, Egypt. J. Am. Sci. 2011, 7, 840-848.

7. Fattore, E.; Paiano, V.; Borgini, A.; Tittarelli, A.; Bertoldi, M.; Crosignani, P.; Fanelli, R. Human health risk in relation to air quality in two municipalities in an industrialized area of Northern Italy. Environ. Res. 2011, 111, 1321-1327. [CrossRef] [PubMed]

8. Goudarzi, G.; Mohammadi, M.J.; Angali, K.A.; Neisi, A.K.; Babaei, A.A.; Mohammadi, B.; Soleimani, Z.; Geravandi, S. Estimation of Health Effects Attributed to $\mathrm{NO}_{2}$ Exposure Using AirQ Model. Arch. Hyg. Sci. 2012, 1, 59-66.

9. Naddafi, K.; Hassanvand, M.S.; Yunesian, M.; Momeniha, F.; Nabizadeh, R.; Faridi, S.; Gholampour, A. Health impact assessment of air pollution in megacity of Tehran, Iran. Iran. J. Environ. Health Sci. Eng. 2012, 9, 28. [CrossRef] [PubMed]

10. Jeong, S.J. The impact of air pollution on human health in Suwon City. Asian J. Atmos. Environ. 2013, 7, 227-233. [CrossRef] 
11. Habeebullah, T.M. Health impacts of $\mathrm{PM}_{10}$ using AirQ2.2.3 model in Makkah. J. Basic Appl. Sci. 2013, 9, 259-268. [CrossRef]

12. Moustris, K.P.; Proias, G.T.; Larissi, J.K.; Nastos, P.T.; Koukouletsos, K.V.; Paliatsos, A.G. Health impacts due to particulate air pollution in Volos City, Greece. J. Environ. Sci. Health A 2016, 51, 15-20. [CrossRef] [PubMed]

13. The European Parliament and the Council of the European Union. Directive 2008/50/EC of the European Parliament and of the Council on ambient air quality and cleaner air for Europe. Off. J. Eur. Union 2008, 29, 169-212

14. Omidi, Y.; Goudarzi, G.; Heidari, A.M.; Daryanoosh, S.M. Health impact assessment of short-term exposure to $\mathrm{NO}_{2}$ in Kermanshah, Iran using AirQ model. Environ. Health Eng. Manag. J. 2016, 3, 91-97. [CrossRef]

15. Larissi, I.K.; Antoniou, A.; Nastos, P.T.; Paliatsos, A.G. The role of wind in the configuration of the ambient air quality in Athens, Greece. Fresenius Environ. Bull. 2010, 19, 1989-1996.

16. Larissi, I.K.; Koukouletsos, K.V.; Moustris, K.P.; Antoniou, A.; Paliatsos, A.G. PM $_{10}$ concentration levels in the greater Athens area, Greece. Fresenius Environ. Bull. 2010, 19, 226-231.

17. Paschalidou, A.K.; Kassomenos, P.; Karanikola, P. Disaggregating the contribution of local dispersion and long-range transport to the high $\mathrm{PM}_{10}$ values measured in a Mediterranean urban environment. Sci. Total Environ. 2015, 527-528, 119-125. [CrossRef] [PubMed]

18. Aleksandropoulou, V.; Lazaridis, M. Identification of the influence of African dust on $\mathrm{PM}_{10}$ concentrations at the Athens air quality monitoring network during the period 2001-2010. Aerosol. Air Qual. Res. 2013, 13, 1492-1503. [CrossRef]

(C) 2017 by the authors; licensee MDPI, Basel, Switzerland. This article is an open access article distributed under the terms and conditions of the Creative Commons Attribution (CC BY) license (http://creativecommons.org/licenses/by/4.0/). 